Received: 20 March 2017

Accepted: 5 May 2017

Published online: 14 June 2017

\section{Core-multishell globular oxidation in a new TiAINbCr alloy at high temperatures}

\author{
S. Q. Tang ${ }^{1}$, S. J. $Q u^{1}$, A. H. Feng ${ }^{1}$, C. Feng ${ }^{1}$, J. Shen ${ }^{1}$ \& D. L. Chen ${ }^{2}$
}

Oxidation resistance is one of key properties of titanium aluminide (TiAl) based alloys for hightemperature applications such as in advanced aero-engines and gas turbines. A new TiAINbCr alloy with micro-addition of yttrium has been developed, but its oxidation behavior is unknown. To provide some fundamental insights, high-temperature oxidation characteristics of this alloy are examined via scanning electron microscopy, transmission electron microscopy, electron probe microanalysis, and $\mathrm{X}$-ray diffraction. We show that distinctive core-multishell globular oxidation and "daisy" flower-like oxidation occur exclusively around $\mathrm{Y}_{2} \mathrm{O}_{3}$ particles. Globular oxides exhibit multi-layered $\mathrm{Y}_{2} \mathrm{O}_{3} / \mathrm{TiO}_{2} /$ $\mathrm{Al}_{2} \mathrm{O}_{3}$-rich/TiO -rich shell structures from the inside to outside. Flower-like inner oxides consist of core $\mathrm{Y}_{2} \mathrm{O}_{3}$ particles surrounded by divergent $\mathrm{Al}_{2} \mathrm{O}_{3}$ and oxygen-rich $\alpha_{2}-\mathrm{Ti}_{3} \mathrm{Al}$ in the near-scale substrate. As the scale-substrate interface moves inward, the inner oxide structures suffer deeper oxidation and transform into the globular oxide structures. Our results demonstrate that the unique oxidation characteristics and the understanding of formation mechanisms pave the way for the exploration and development of advanced oxidation-resistant TiAl-based materials.

Titanium aluminide (TiAl) based alloys are considered to be a new class of promising advanced high-temperature structural materials in the aerospace, gas turbine and automotive industries, because of their lightweighting with a low density $\left(3.9-4.2 \mathrm{~g} / \mathrm{cm}^{3}\right)$, high specific yield strength and stiffness, and superior creep resistance at elevated temperatures ${ }^{1-6}$. This is highly inspired by the recent successful application of a TiAl-based alloy in General Electric's high-thrust GEnex jet engines for powering Boeing 747-8 and 787 Dreamliner, to substitute $\mathrm{Ni}$-based superalloys in the temperature range of $650-750^{\circ} \mathrm{C}$ with the benefit of a weight reduction of $\sim 50 \%{ }^{1-3}$. However, their wide commercial applications are still limited due to low room-temperature ductility ${ }^{7,8}$, lack of a cost-effective processing method, and unsatisfactory oxidation resistance at temperatures above $750^{\circ} \mathrm{C}^{9,10}$. Unlike $\mathrm{Ni}$-Al alloys, no protective $\mathrm{Al}_{2} \mathrm{O}_{3}$ layer could occur on the titanium aluminide alloys because both titanium and aluminum form oxides of similar stability ${ }^{11}$. Therefore, many measures were taken to improve the oxidation resistance of titanium aluminide alloys such as surface treatment ${ }^{12,13}$ and coating technologies ${ }^{14-16}$. In particular, both mechanical properties and oxidation resistance at high temperatures can be simultaneously improved via adding moderate ternary or quartic elements such as niobium ${ }^{17}$, tungsten, silicon, molybdenum ${ }^{18}$, chromium $^{19}$ and yttrium ${ }^{20}$ in binary titanium aluminide alloys $\mathrm{s}^{21,22}$. Yttrium exhibits a strong grain refinement effect, thus improving the tensile strength of TiAl-based alloys ${ }^{23,24}$. The addition of yttrium also significantly improves oxidation resistance due to its strong affinity to oxygen ${ }^{20,23,25,26}$. Oxide pegs protruding into the substrate ${ }^{26}$ and convex-shaped nail-like oxides ${ }^{25}$ were observed at the scale-substrate interface, which play an important role in anchoring the oxide scale and improving anti-spalling ability of the scale on the surface of titanium aluminide alloys with an addition of yttrium. However, it is unclear how and in which form the oxidation occurs at high temperatures. In the present study, a new type of core-multishell globular oxide structure consisting of different oxide layers formed in a newly-developed Ti-44Al-4Nb-1.5Cr-0.5Mo-0.1B-0.1Y alloy induced by the presence of yttrium oxide $\left(\mathrm{Y}_{2} \mathrm{O}_{3}\right)$ particles during oxidation at a high temperature of $900^{\circ} \mathrm{C}$ is observed and discussed. Special attention is paid to the formation and growth mechanism of this unique type of globular oxides to give underlying insights about the effect of yttrium on the oxidation process of titanium aluminide alloys.

${ }^{1}$ School of Materials Science and Engineering, Tongji University, Shanghai, 201804, P.R. China. ${ }^{2}$ Department of Mechanical and Industrial Engineering, Ryerson University, Toronto, Ontario, M5B 2K3, Canada. Correspondence and requests for materials should be addressed to J.S. (email: junshen@tongji.edu.cn) or D.L.C. (email: dchen@ ryerson.ca) 

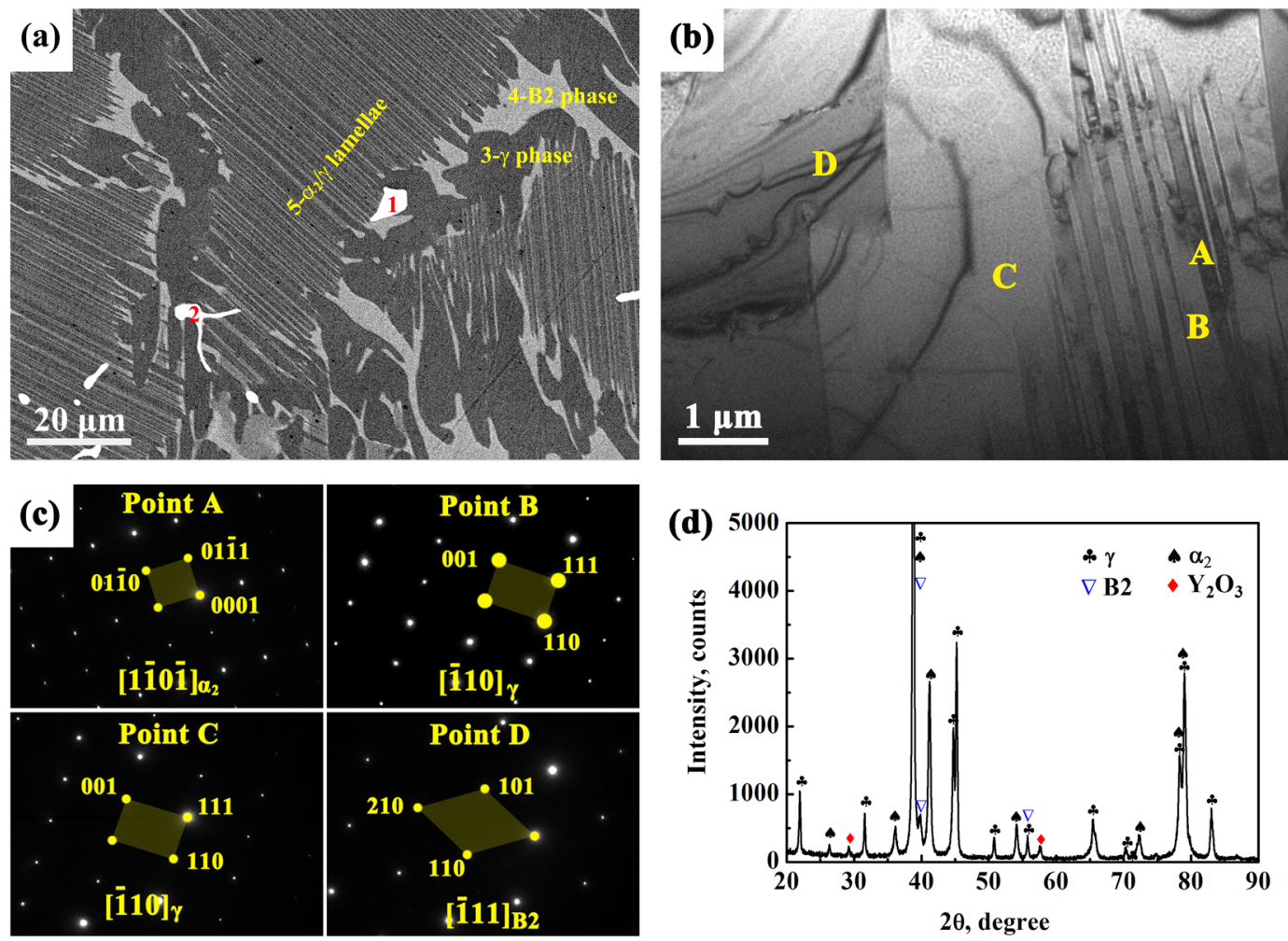

Figure 1. Microstructures of as-cast TiAlNbCr alloy. (a) SEM back-scattered electron micrograph showing gray $\alpha_{2}-\mathrm{Ti}_{3} \mathrm{Al}$ and dark $\gamma$-TiAl lamellae, white $\mathrm{B} 2$-phase, and bright white $\mathrm{Y}_{2} \mathrm{O}_{3}$ particles, (b) TEM bright field image along with (c) the corresponding selected area diffraction (SAD) patterns of points A-D, where A represents $\alpha_{2}-\mathrm{Ti}_{3} \mathrm{Al}$ lamella, B corresponds to $\gamma$-TiAl lamella, C indicates $\gamma$-TiAl, and D stands for B2, and (d) XRD pattern further confirming the presence of $\alpha_{2}-\mathrm{Ti}_{3} \mathrm{Al}, \gamma$-TiAl, B2-phase and $\mathrm{Y}_{2} \mathrm{O}_{3}$ particles.

\begin{tabular}{|l|l|l|l|l|l|l|l|l|l|}
\hline Number & Ti & Al & Nb & Cr & Mo & B & Y & O & N \\
\hline 1 & 4.94 & 3.27 & 0.29 & 0.12 & 0.03 & 0 & 38.19 & 53.16 & 0 \\
\hline 2 & 4.95 & 3.63 & 0.31 & 0.17 & 0.01 & 0 & 38.10 & 52.84 & 0 \\
\hline 3 & 49.02 & 45.62 & 4.32 & 0.92 & 0.12 & 0 & 0 & - & - \\
\hline 4 & 58.26 & 31.92 & 5.14 & 3.65 & 1.04 & 0 & 0 & - & - \\
\hline 5 & 52.91 & 41.82 & 3.86 & 1.23 & 0.19 & 0 & 0 & - & - \\
\hline
\end{tabular}

Table 1. Elemental composition (at.\%) determined via EPMA at points 1-5 in Fig. 1(a).

\section{Results}

Microstructures of TiAINbCr alloy. Back-scattered electron (BSE) SEM micrograph, TEM bright field image along with the relevant selected area diffraction (SAD) patterns, and XRD pattern of as-cast TiAlNbCr alloy are shown in Fig. 1(a) through (d). The elemental compositions of points marked by "1" to " 5 " in Fig. 1(a) via electron probe microanalysis (EPMA) are summarized in Table 1. These analyses revealed that the microstructure consisted mainly of white B2-phase, dark $\gamma$-TiAl phase at colony (or grain) boundaries, which has an ordered $\mathrm{L} 1_{0}$ structure, gray $\alpha_{2}-\mathrm{Ti}_{3} \mathrm{Al}$, which has an ordered hexagonal $\mathrm{D} 0_{19}$ structure, and $\alpha_{2} / \gamma$ lamellar colonies as identified by the SAD and XRD patterns in Fig. 1. This is also corroborated via EPMA point chemical microanalyses, where points " 3 ", " 4 " and " 5 " corresponded to $\gamma$-TiAl, ordered titanium with B2 structure and $\alpha_{2} / \gamma$ lamellar colony, respectively. The disordered $\beta$ phase existing at high temperatures, which exhibits multiple slip systems due to its body-centered cubic crystal structure, will transform into the brittle B2-ordered phase in Ti-Al alloys at room temperature ${ }^{5,22}$. Therefore, the volume fraction of B2 phase should be carefully controlled. Points " 1 " and " 2 " and other bright white particles imbedded in $\alpha_{2} / \gamma$ lamellar colonies were identified to be $\mathrm{Y}_{2} \mathrm{O}_{3}$ particles. However, $\mathrm{YAl}_{2}$ compounds reported in other TiAl-based alloys with yttrium addition ${ }^{26}$ were not observed in the present TiAlNbCr alloy.

Isothermal oxidation kinetics. Figure 2 shows a curve of isothermal oxidation kinetics of TiAlNbCr alloy at $900^{\circ} \mathrm{C}$. The obtained weight gain of this alloy after $100 \mathrm{~h}$ at $900^{\circ} \mathrm{C}$ was about $2.3777 \mathrm{mg} / \mathrm{cm}^{2}$. To identify which law of oxidation kinetics is followed, the obtained experimental data could be fitted using the following equation, 


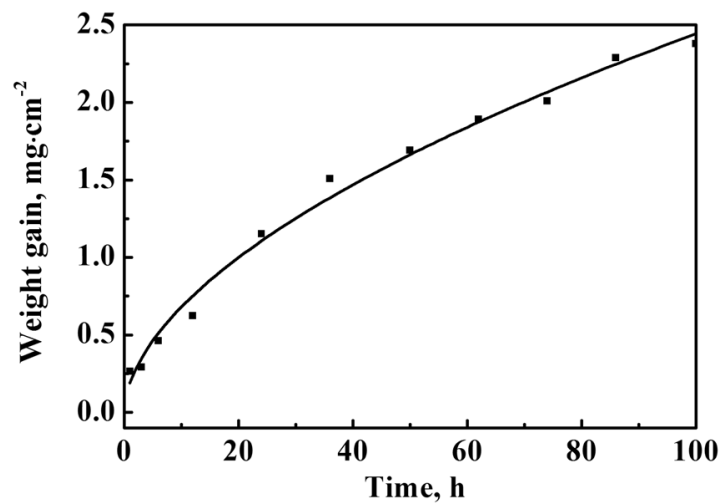

Figure 2. Oxidation kinetics of TiAlNbCr alloy at $900^{\circ} \mathrm{C}$ up to $100 \mathrm{~h}$. Weight gain per unit area as a function of time.
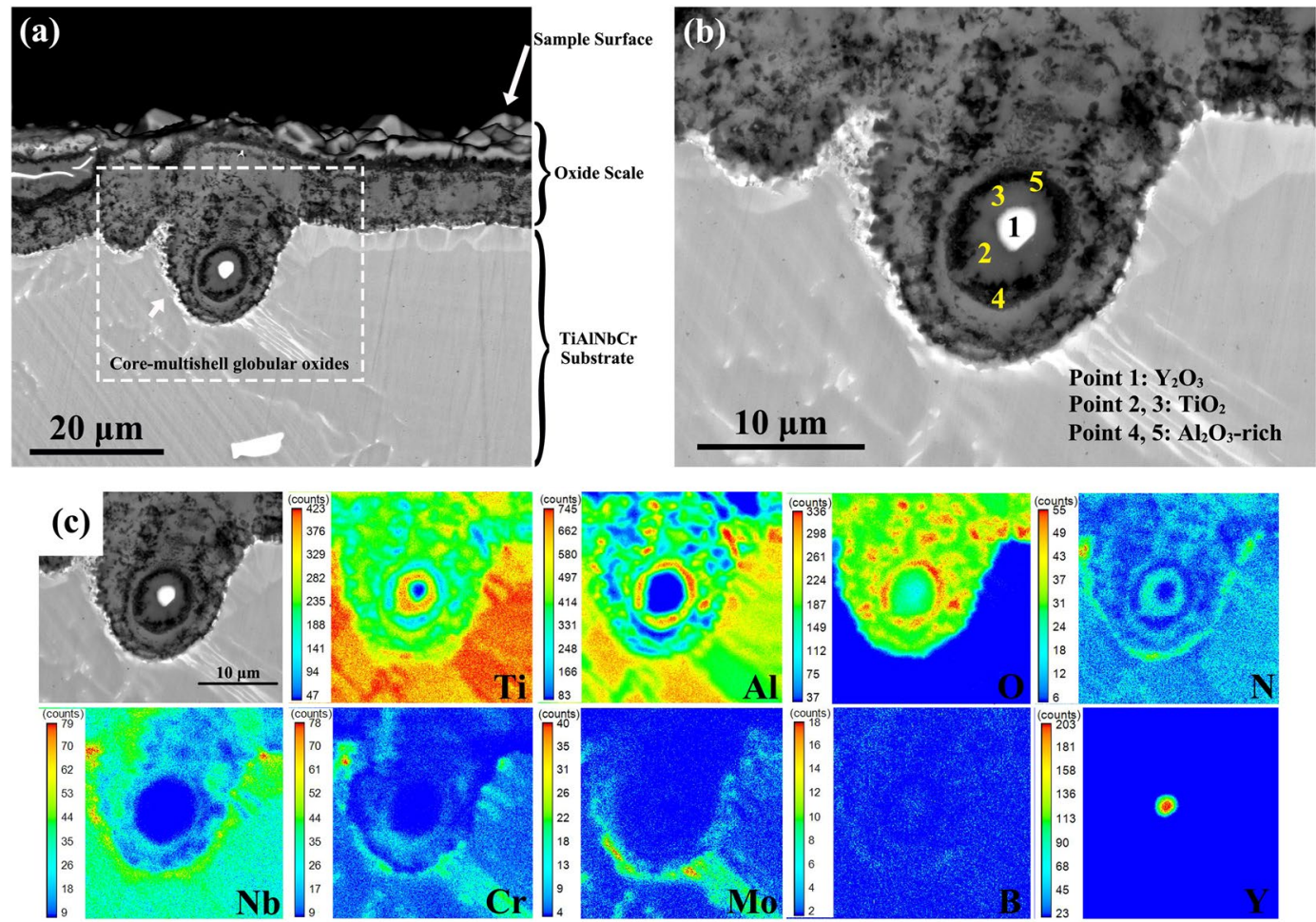

Figure 3. A typical core-multishell globular oxide of TiAlNbCr alloy after oxidation at $900^{\circ} \mathrm{C}$ for $100 \mathrm{~h}$. (a) and (b) Morphologies of oxides with a globular structure, which consist of a core $\mathrm{Y}_{2} \mathrm{O}_{3}$ particle and multi-layered $\mathrm{TiO}_{2} / \mathrm{Al}_{2} \mathrm{O}_{3}$-rich $/ \mathrm{TiO}_{2}$-rich shells from the inside to outside, and (c) elemental distributions via EPMA mapping for the globular oxide, where the detailed chemical microanalysis results are shown in Table 2.

$$
\Delta M^{n}=k_{n} t
$$

where $\Delta M$ represents weight gain per unit area $\left(\mathrm{mg} / \mathrm{cm}^{2}\right), n$ is an oxidation exponent $(n=1$, linear relationship; $n=2$, parabolic relationship), $k_{n}$ is a rate constant $\left(\mathrm{mg}^{\mathrm{n}} / \mathrm{cm}^{2 \mathrm{n}} \mathrm{h}\right)$ and $t$ is oxidation time (h). The obtained oxidation exponent was close to 2 , suggesting that the oxidation kinetics of TiAlNbCr alloy at $900{ }^{\circ} \mathrm{C}$ obeyed a parabolic relationship.

Core-multishell globular oxidation. Figure 3(a) and (b) shows the cross-sectional morphology of a typical oxide with globular structures after oxidation at $900^{\circ} \mathrm{C}$ for $100 \mathrm{~h}$. The globular oxides were normally located inside or underneath the oxide scale and they were also observed in all other specimens after oxidation at $900^{\circ} \mathrm{C}$ for 12, 24 and $50 \mathrm{~h}$. The bright white core of the globular oxide marked by "1" in Fig. 3(b) was identified to be $\mathrm{Y}_{2} \mathrm{O}_{3}$ according to EPMA point chemical microanalysis results shown in Table 2 and EPMA elemental distribution maps in Fig. 3(c). The adjacent gray loop marked by "2" and " 3 " and outer dark loop marked by " 4 " and " 5 " 


\begin{tabular}{|l|l|l|l|l|l|l|l|l|l|l|}
\hline Number & $\mathbf{T i}$ & $\mathbf{A l}$ & $\mathbf{N b}$ & $\mathbf{C r}$ & $\mathbf{M o}$ & $\mathbf{B}$ & $\mathbf{Y}$ & $\mathbf{O}$ & $\mathbf{N}$ & Remarks \\
\hline 1 & 7.89 & 0.21 & 0.034 & 0.05 & 0.03 & 0 & 36.42 & 55.37 & 0 & $\mathrm{Y}_{2} \mathrm{O}_{3}$ (bright white) \\
\hline 2 & 31.56 & 1.25 & 0.02 & 0.17 & 0.06 & 0 & 0.18 & 62.02 & 4.75 & \multirow{2}{*}{$\mathrm{TiO}_{2}$ (gray) } \\
\hline 3 & 27.11 & 7.74 & 0.06 & 0.20 & 0.06 & 0 & 0.35 & 60.27 & 4.22 & \\
\hline 4 & 12.31 & 22.31 & 0.23 & 0.59 & 0.08 & 0 & 0.35 & 62.79 & 1.35 & \multirow{2}{*}{$\mathrm{Al}_{2} \mathrm{O}_{3}$-rich (dark) } \\
\hline 5 & 12.07 & 23.55 & 0.51 & 0.35 & 0.04 & 0 & 0.22 & 62.17 & 1.10 & \\
\hline
\end{tabular}

Table 2. Elemental composition (at.\%) determined via EPMA at 1-5 points in Fig. 3(b).
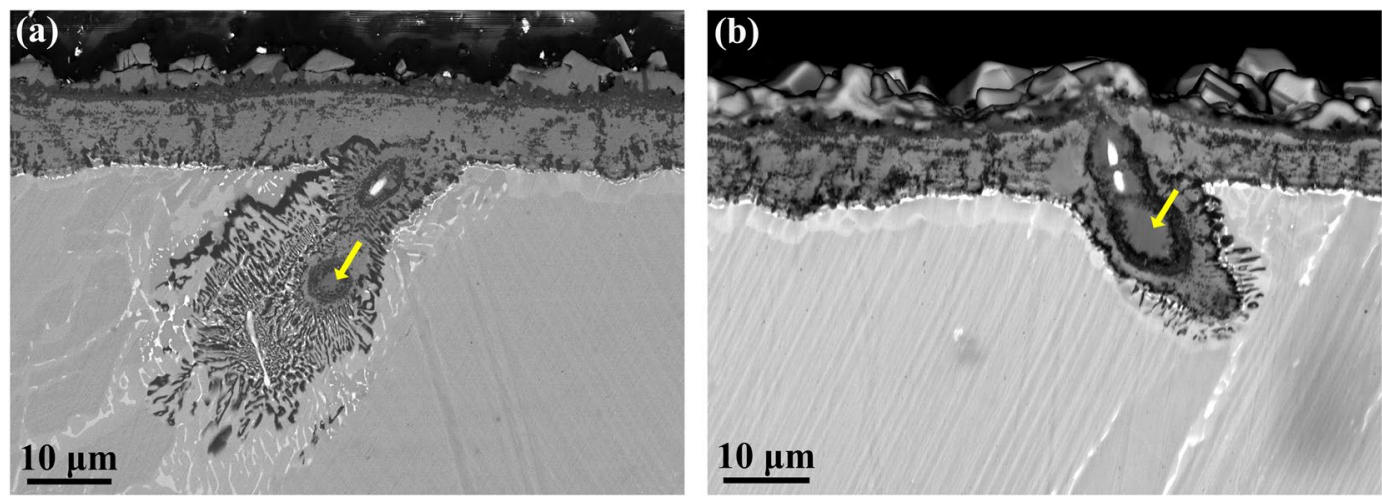

Figure 4. Typical micrographs showing transient core-shell globular oxides in TiAlNbCr alloy after oxidation at $900^{\circ} \mathrm{C}$ for $100 \mathrm{~h}$. (a) and (b) Morphologies of two oxides with a transient or incomplete core-shell globular structure at an intermediate distance to the scale-substrate interface.


Figure 5. "Daisy" flower-like morphologies of an inner oxide after oxidation at $900^{\circ} \mathrm{C}$ for $50 \mathrm{~h}$. (a) A lowmagnification image showing the location of inner oxide with respect to the scale-substrate interface, and (b) a magnified image of Fig. 3(a) showing the oxide details consisting of a core $\mathrm{Y}_{2} \mathrm{O}_{3}$ particle surrounded by divergent $\mathrm{Al}_{2} \mathrm{O}_{3}$ and oxygen-rich $\alpha_{2}-\mathrm{Ti}_{3} \mathrm{Al}$, where the EPMA microanalysis locations are marked by " 1 "- " 7 " with the obtained results summarized in Table 3.

in Fig. 3(b) were confirmed as $\mathrm{TiO}_{2}$ and $\mathrm{Al}_{2} \mathrm{O}_{3}$-rich shells, respectively. The outermost layer of $\mathrm{TiO}_{2}$-rich shell in this globular oxide contacted with the $\mathrm{TiO}_{2}+\mathrm{Al}_{2} \mathrm{O}_{3}$ mixture layer of the oxide scale. Therefore, the globular oxide structure consisted of a core $\mathrm{Y}_{2} \mathrm{O}_{3}$ particle and multi-layered $\mathrm{TiO}_{2} / \mathrm{Al}_{2} \mathrm{O}_{3}$-rich/TiO -rich shells from the inside to outside. This kind of oxides protruding into the substrate could improve the adhesion of scale ${ }^{25,26}$. It should be noted that transient or incomplete core-shell globular oxidation could also be observed, as shown in Fig. 4. This was mainly dependent on the oxidation time or the location of $\mathrm{Y}_{2} \mathrm{O}_{3}$ particles (i.e., the distance of $\mathrm{Y}_{2} \mathrm{O}_{3}$ particles to the scale-substrate interface). Additionally, while some $\mathrm{Y}_{2} \mathrm{O}_{3}$ particles were embedded or buried beneath the polished surface, as indicated by arrows in Fig. 4(a) and (b), they still induced the core-shell like globular oxidation. Such embedded $\mathrm{Y}_{2} \mathrm{O}_{3}$ particles were expected to be shallowly positioned just under the surface skin.

"Daisy" flower-like inner oxidation. It is also of special interest to observe a unique type of "daisy" flower-like inner oxides present in the alloy substrate close to the oxide scale (but without linking to the scale-substrate interface), as shown in Fig. 5(a) and (b). This was unlike the situation of inner oxides in other 


\begin{tabular}{|c|c|c|c|c|c|c|c|c|c|c|}
\hline Number & Ti & $\mathrm{Al}$ & $\mathrm{Nb}$ & $\mathrm{Cr}$ & Mo & B & $\mathbf{Y}$ & O & $\mathrm{N}$ & Remarks \\
\hline 1 & 3.99 & 1.28 & 0.24 & 0.04 & 0 & 0 & 36.91 & 57.54 & 0 & $\mathrm{Y}_{2} \mathrm{O}_{3}$ (bright white) \\
\hline 2 & 16.46 & 31.68 & 1.26 & 1.00 & 0.06 & 0 & 0 & 46.72 & 2.82 & \multirow{2}{*}{$\mathrm{Al}_{2} \mathrm{O}_{3}$-rich (dark) } \\
\hline 3 & 21.58 & 24.06 & 1.55 & 0.37 & 0.08 & 0 & 0.01 & 50.59 & 1.77 & \\
\hline 4 & 40.98 & 24.66 & 2.36 & 1.06 & 0.12 & 0 & 0 & 23.63 & 7.19 & \multirow{2}{*}{ Al-depleted (gray) } \\
\hline 5 & 44.64 & 23.63 & 3.44 & 0.85 & 0.22 & 0 & 0 & 18.92 & 8.30 & \\
\hline 6 & 43.41 & 32.48 & 3.08 & 0.88 & 0.17 & 0 & 0 & 9.17 & 10.80 & \multirow{2}{*}{ Substrate } \\
\hline 7 & 41.93 & 32.91 & 3.10 & 0.96 & 0.15 & 0 & 0 & 8.91 & 12.05 & \\
\hline
\end{tabular}

Table 3. Elemental composition (at.\%) determined via EPMA at points 1-7 in Fig. 5(b).

alloys, such as intergranular internal oxides and internal-oxide band ${ }^{27}$. In the present study, all the inner oxide structures exclusively centered on a bright white particle. EPMA point chemical microanalysis results of points marked by "1"- "7" in Fig. 5(b) were summarized in Table 3 and the bright white core marked by "1" was again determined to be $\mathrm{Y}_{2} \mathrm{O}_{3}$ particle. At points " 2 " and " 3 ", the concentration of aluminum was higher than that of titanium, which was in contrast to points " 6 " and " 7 " in the lamellar colony of substrate. This means that aluminum with a higher chemical activity at high temperatures was preferentially oxidized to form the divergent inner $\mathrm{Al}_{2} \mathrm{O}_{3}$ oxides around $\mathrm{Y}_{2} \mathrm{O}_{3}$ particles in the substrate. Points " 4 " and " 5 " close to the inner oxides were speculated as $\mathrm{\alpha}_{2}-\mathrm{Ti}_{3} \mathrm{Al}$ rich in oxygen. This was likely due to the fact that (1) the formation of inner $\mathrm{Al}_{2} \mathrm{O}_{3}$ consumed aluminum which led to an increase of the relative concentration of titanium; (2) the saturation concentration of oxygen in the $\alpha_{2}-\mathrm{Ti}_{3} \mathrm{Al}$ and $\gamma-\mathrm{TiAl}$ alloys was calculated to be $16 \%$ and $2 \%$, respectively ${ }^{28}$, and the oxygen concentration at points " 4 " and " 5 " were about $23.6 \%$ and $18.9 \%$ which were closer to $16 \%$. However, the inner oxides embedded in the substrate may be detrimental to the mechanical properties ${ }^{29,30}$.

\section{Discussion}

Yttrium with a low concentration of $0.1 \%$ was added in our TiAlNbCr alloy aiming to remove the oxygen which was present in the alloy in the process of smelting. This goal was successfully achieved due to the reaction of yttrium with oxygen to form $\mathrm{Y}_{2} \mathrm{O}_{3}$ particles, as shown in Fig. 1(a). After high-temperature oxidation at $900{ }^{\circ} \mathrm{C}, \mathrm{Y}_{2} \mathrm{O}_{3}$ particles were still stable and remained unchanged. However, they were observed to induce high-temperature oxidation and occupy the cores of both globular oxide structures and "daisy" flower-like inner oxide structures. Globular oxides were positioned inside or underneath the oxide scale on the surface, which were directly linked to the scale (Fig. 3), while the characteristic flower-like inner oxidation occurred within the substrate in the vicinity of scale-substrate interface (Fig. 5). This suggests that the area surrounding $\mathrm{Y}_{2} \mathrm{O}_{3}$ particles was susceptible to oxidation at a high temperature of $900^{\circ} \mathrm{C}$. As the oxidation continued, the scale-substrate interface moved inwards and flower-like inner oxide structures were increasingly oxidized and eventually become the globular oxide structures (Fig. 4). It was as if the "daisy" flower-like inner oxide structures were the precursor of the globular oxide structures and the $\mathrm{Y}_{2} \mathrm{O}_{3}$ particles were the seeds of oxidation at high temperatures.

Figure 6 illustrates the formation and growth mechanism of the core-multishell globular oxide structures in the TiAlNbCr alloy during high-temperature oxidation. First, a thin oxide scale formed on the surface in conjunction with the inward diffusion of oxygen and nitrogen as seen in "Stage 1". Then aluminum, which was more active than titanium at a high temperature of $900^{\circ} \mathrm{C}$ as seen from their standard free energy of oxidation as a function of temperature ${ }^{31}$, reacted with the penetrated oxygen preferentially near the interface between $\mathrm{Y}_{2} \mathrm{O}_{3}$ particles and substrate to form flower-like inner oxides as shown in Fig. 5. $\mathrm{Al}_{2} \mathrm{O}_{3}$ firstly formed at the $\mathrm{Y}_{2} \mathrm{O}_{3}$-substrate interface and the reasons could be considered as follows:

(a) The $\mathrm{Y}_{2} \mathrm{O}_{3}$-substrate interfacial energy could be lowered when the nucleation of $\mathrm{Al}_{2} \mathrm{O}_{3}$ occurred there.

(b) The local tensile stresses existent in the nearby substrate arising from the nucleation and growth of $\mathrm{Y}_{2} \mathrm{O}_{3}$ could drive the formation of inner oxides ${ }^{32}$.

(c) The tensile stresses present at the $\mathrm{Y}_{2} \mathrm{O}_{3}$-substrate interface could result in the formation of microvoids or other defects at the interface which provided a growing space of $\mathrm{Al}_{2} \mathrm{O}_{3}$ or fast diffusion channel of oxygen ${ }^{27,32}$.

With the consumption of aluminum, $\alpha_{2}-\mathrm{Ti}_{3} \mathrm{Al}$ rich in oxygen formed in the $\mathrm{Al}$-depleted areas beside divergent inner $\mathrm{Al}_{2} \mathrm{O}_{3}$ products as shown in "Stage 2". In "Stage 3", the scale-substrate interface continued to move inward and contacted with the flower-like inner oxide. Then $\mathrm{TiO}_{2}$ formed preferentially in $\alpha_{2}-\mathrm{Ti}_{3} \mathrm{Al}(\mathrm{O})^{33}$ perpendicular to divergent $\mathrm{Al}_{2} \mathrm{O}_{3}$ along with two aluminum-rich layers. The previously formed $\mathrm{Al}_{2} \mathrm{O}_{3}$ was thus broken up and dissolved into $\mathrm{TiO}_{2}$ lattice, because of the volume expansion caused by the formation of $\mathrm{TiO}_{2}{ }^{34}$. The so-called fast-grown $\mathrm{TiO}_{2}{ }^{35}$, rapidly moved around $\mathrm{Y}_{2} \mathrm{O}_{3}$ particle to form a full $\mathrm{TiO}_{2}$-rich shell mingled with a small amount of $\mathrm{Al}_{2} \mathrm{O}_{3}$, along with an inner aluminum-rich shell as shown in "Stage 4". In the subsequent oxidation in "Stage 5", $\mathrm{Al}_{2} \mathrm{O}_{3}$ preferentially grew in the inner aluminum-rich shell because of the higher relative activity of aluminum, leading to an $\mathrm{Al}_{2} \mathrm{O}_{3}$-rich shell as seen at points " 4 " and " 5 " in Fig. 3(b), and the formation of an aluminum-depleted shell directly adjoining to the central $\mathrm{Y}_{2} \mathrm{O}_{3}$ particle. Finally, in "Stage 6" this innermost aluminum-depleted shell was replaced by $\mathrm{TiO}_{2}$ as oxygen diffused inward via a certain extent of break-up and dissolution of the previously-formed neighboring $\mathrm{Al}_{2} \mathrm{O}_{3}$ oxides in the form ${ }^{36}$,

$$
\mathrm{Al}_{2} \mathrm{O}_{3}=2 \mathrm{Al}^{3+}+\frac{3}{2} \mathrm{O}_{2}+6 e^{-} .
$$



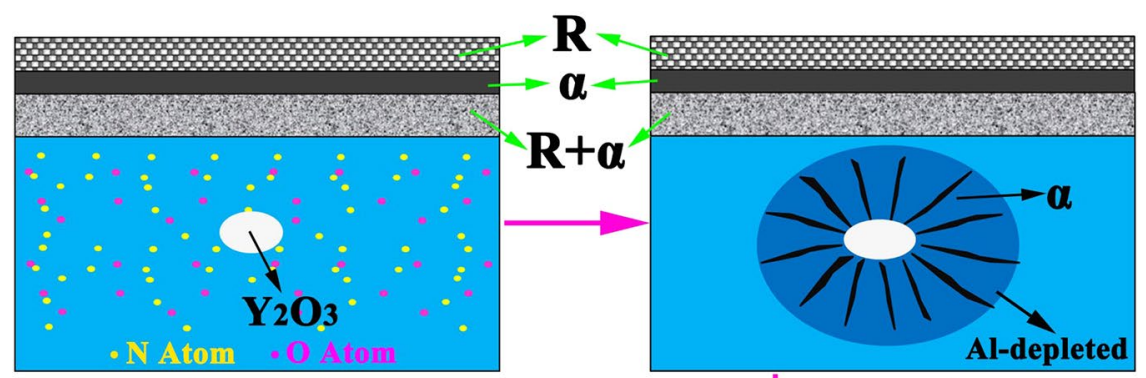

Stage 1
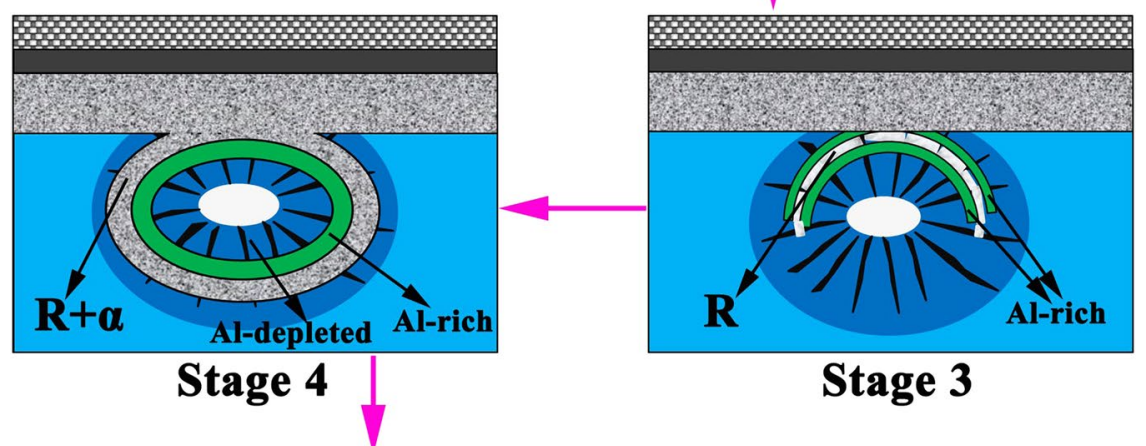

Stage 3

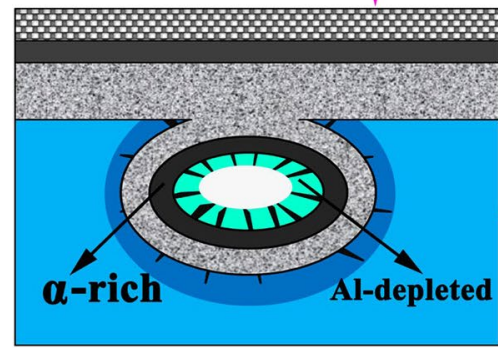

Stage 5

\section{R: $\mathrm{TiO}_{2} \quad \alpha: \mathrm{Al}_{2} \mathrm{O}_{3}$}

Figure 6. Formation and growth process of a distinctive core-multishell globular oxide in the TiAlNbCr alloy during high-temperature oxidation. Stage 1, inward diffusion of oxygen and nitrogen; Stage 2, aluminum reacted with the penetrated oxygen preferentially near the interface between $\mathrm{Y}_{2} \mathrm{O}_{3}$ particle and substrate to form a flower-like inner oxide; Stage 3, formation of a partial $\mathrm{TiO}_{2}$-rich shell mingled with a small amout of $\mathrm{Al}_{2} \mathrm{O}_{3}$; Stage 4, formation of a full $\mathrm{TiO}_{2}$-rich shell mingled with $\mathrm{Al}_{2} \mathrm{O}_{3}$, along with an inner aluminum-rich shell; Stage 5 , formation of an $\mathrm{Al}_{2} \mathrm{O}_{3}$ shell; and Stage 6, formation of the innermost $\mathrm{TiO}_{2}$ shell.

As a result, little aluminum was detected in the innermost $\mathrm{TiO}_{2}$ shell as shown at points " 2 " and " 3 " in Fig. 3(b). The generated $\mathrm{Al}^{3+}$ interstitial ions via Equ. (2) may escape via the outer mingled shell of $\mathrm{TiO}_{2}$ and $\mathrm{Al}_{2} \mathrm{O}_{3}$ to compensate the outermost aluminum-depleted shell in Stage 5, leading to its disappearance and a wider mingled shell ("Stage 6" in Fig. 6).

In conclusion, a minor addition of $0.1 \%$ yttrium in the TiAlNbCr alloy led to the formation of $\mathrm{Y}_{2} \mathrm{O}_{3}$ particles, together with B2-phase, $\gamma$-TiAl and $\alpha_{2}-\mathrm{Ti}_{3} \mathrm{Al} / \gamma$-TiAl lamellar structures. The presence of $\mathrm{Y}_{2} \mathrm{O}_{3}$ particles was responsible for the occurrence of two distinctive characteristics of oxidation at high temperatures: core-multishell globular oxidation and "daisy" flower-like oxidation, which were observed for the first time, to the best of our knowledge. The globular oxide structures consisted of a core $\mathrm{Y}_{2} \mathrm{O}_{3}$ particle and multi-layered $\mathrm{TiO}_{2} / \mathrm{Al}_{2} \mathrm{O}_{3}$-rich/ $\mathrm{TiO}_{2}$-rich shells from the inside to outside, while the flower-like inner oxide structures exhibited a core $\mathrm{Y}_{2} \mathrm{O}_{3}$ particle surrounded by the divergent $\mathrm{Al}_{2} \mathrm{O}_{3}$ and oxygen-rich $\alpha_{2}-\mathrm{Ti}_{3} \mathrm{Al}$ within the substrate in the neighborhood of oxide scale. As the scale-substrate interface moved inward, the inner flower-like oxide structures underwent increasingly more severe oxidation and eventually transformed into the globular oxide structures. We anticipate that the findings of unique oxidation characteristics and the understanding of relevant formation mechanisms pave the way for the exploration and development of advanced oxidation-resistant TiAl-based materials for the high-temperature applications.

\section{Materials and Methods}

The titanium aluminide alloy selected in this study with a nominal chemical composition of Ti-44Al-4Nb$1.5 \mathrm{Cr}-0.5 \mathrm{Mo}-0.1 \mathrm{~B}-0.1 \mathrm{Y}$ (in at.\%, and hereafter referred to as TiAlNbCr alloy) was prepared by double vacuum 
consumable arc melting technique. The test specimens with a size of $10 \times 10 \times 3 \mathrm{~mm}^{3}$ were cut from the cast ingot by electro-discharge machining. The surfaces of the specimens were polished with 1200 -grit $\mathrm{SiC}$ papers, and then cleaned ultrasonically in acetone for $15 \mathrm{~min}$ before isothermal oxidation in air at $900^{\circ} \mathrm{C}$. To avoid that one of the specimen surfaces came into contact with a flat crucible and ensure that all of the specimen surfaces were fully exposed to the air during isothermal oxidation tests, the specimens were first placed into the hollow ceramic cylinders positioned horizontally in a larger flat crucible. Then the crucible was transferred into the furnace. The specimens after oxidation were weighed for determining the weight gain, and subsequently mounted with resin and polished to a mirror-like surface. To increase electrical conductivity and image resolution, the polished specimens were carbon-coated before scanning electron microscope (SEM) and electron probe microanalysis (EPMA) examinations. Elemental distributions of titanium, aluminum, oxygen, nitrogen, niobium, chromium, molybdenum, boron and yttrium were detected through EPMA and the corresponding standard samples used for calibration were pure titanium, $\mathrm{Al}_{2} \mathrm{O}_{3}, \mathrm{BN}$, pure niobium, pure chromium, pure molybdenum, pure boron and $\mathrm{YP}_{4} \mathrm{O}_{12}$, respectively. X-ray diffraction (XRD) was used to identify phases in the alloy with a diffraction angle $(2 \theta)$ from $10^{\circ}$ to $100^{\circ}$ with a step size of $0.02^{\circ}$ and $1 \mathrm{~s}$ in each step.

\section{References}

1. Pollock, T. M. Alloy design for aircraft engines. Nature Mater. 15, 809-815 (2016).

2. Chen, G. et al. Polysynthetic twinned TiAl single crystals for high-temperature applications. Nature Mater. 15, 876-882 (2016).

3. Schutze, M. High-temperature alloys: Single-crystal performance boost. Nature Mater. 15, 823-824 (2016).

4. Devaraj, A. et al. A low-cost hierarchical nanostructured beta-titanium alloy with high strength. Nature Commun. 7, 11176 (2016).

5. Appel, F., Clemens, H. \& Fischer, F. D. Modeling concepts for intermetallic titanium aluminides. Prog. Mater. Sci. 81, 55-124 (2016).

6. Yu, L., Song, X. P., You, L., Jiao, Z. H. \& Yu, H. C. Effect of dwell time on creep-fatigue life of a high-Nb TiAl alloy at $750{ }^{\circ} \mathrm{C}$. Scripta Mater. 109, 61-63 (2015).

7. Bewlay, B. P., Nag, S., Suzuki, A. \& Weimer, M. J. TiAl alloys in commercial aircraft engines. Materials at High Temperatures 33, 549-559 (2016)

8. Edwards, T. E. J., Gioacchino, F. D., Moreno, R. M. \& Clegg, W. J. Deformation of lamellar TiAl alloys by longitudinal twinning. Scripta Mater. 118, 46-50 (2016).

9. Maurice, V., Despert, G., Zanna, S., Bacos, M. P. \& Marcus, P. Self-assembling of atomic vacancies at an oxide/intermetallic alloy interface. Nature Mater. 3, 687-691 (2004).

10. Froehlich, M., Braun, R. \& Leyens, C. Oxidation resistant coatings in combination with thermal barrier coatings on gamma-TiAl alloys for high temperature applications. Surf. Coat. Tech. 201, 3911-3917 (2006).

11. Reddy, R. G., Wen, X. \& Divakar, M. Isothermal oxidation of TiAl alloy. Metall. Mater. Trans. A 32, 2357-2361 (2001).

12. Xiong, H. P. et al. Liquid-phase siliconizing by Al-Si alloys at the surface of a TiAl-based alloy and improvement in oxidation resistance. Acta Mater. 52, 2605-2620 (2004).

13. Brou, S. Y., Siab, R., Bonnet, G. \& Grosseau-Poussard, J. L. On dipping of gamma-TiAl in low-concentration phosphoric acid solution and consecutive oxidation resistance at $800^{\circ} \mathrm{C}$. Scripta Mater. 56, 517-520 (2007).

14. Li, Z. W., Gao, W. \& He, Y. D. Protection of a Ti ${ }_{3} \mathrm{Al}-\mathrm{Nb}$ alloy by electro-spark deposition coating. Scripta Mater. 45, 1099-1105 (2001).

15. Zhang, P., Flores-Renteria, A., Wild, E., Reimers, W. \& Leyens, C. Oxidation-resistant Ti-90Al coatings with lotus effect surface morphology deposited on a gamma-TiAl alloy. Scripta Mater. 61, 1156-1159 (2009).

16. Yao, J., He, Y., Wang, D. \& Lin, J. High-temperature oxidation resistance of $\left(\mathrm{Al}_{2} \mathrm{O}_{3}-\mathrm{Y}_{2} \mathrm{O}_{3}\right) /\left(\mathrm{Y}_{2} \mathrm{O}_{3}\right.$-stabilized $\left.\mathrm{ZrO} \mathrm{r}_{2}\right)$ laminated coating on $8 \mathrm{Nb}$-TiAl alloy prepared by a novel spray pyrolysis. Corrosion Sci. 80, 19-27 (2014).

17. Jiang, H., Hirohasi, M., Lu, Y. \& Imanari, H. Effect of Nb on the high temperature oxidation of Ti-(0-50 at.\%)Al. Scripta Mater. 46, 639-643 (2002)

18. Shida, Y. \& Anada, H. Role of W, Mo, Nb and Si on oxidation of TiAl in air at high-temperatures. Mater. Trans. JIM 35, 623-631 (1994).

19. Wang, Y., Wang, J. N., Yang, J. \& Zhang, B. Control of a fine-grained microstructure for cast high-Cr TiAl alloys. Mater. Sci. Eng. A 392, 235-239 (2005).

20. Wu, Y., Hagihara, K. \& Umakoshi, Y. Improvement of cyclic oxidation resistance of Y-containing TiAl-based alloys with equiaxial gamma microstructures. Intermetallics 13, 879-884 (2005).

21. Kim, D. et al. Oxidation behaviour of gamma titanium aluminides with or without protective coatings. Inter. Mater. Rev. 59, 297-325 (2014).

22. Lu, Y., Yamada, J., Nakamura, J., Yoshimi, K. \& Kato, H. Effect of B2-ordered phase on the deformation behavior of Ti-Mo-Al alloys at elevated temperature. J. Alloys and Compounds 696, 130-135 (2017).

23. Wu, Y. \& Hwang, S. K. Microstructural refinement and improvement of mechanical properties and oxidation resistance in EPM TiAl-based intermetallics with yttrium addition. Acta Mater. 50, 1479-1493 (2002).

24. Wu, Y. \& Hwang, S. K. The effect of yttrium on microstructure and dislocation behavior of elemental powder metallurgy processed TiAl-based intermetallics. Mater. Lett. 58, 2067-2072 (2004).

25. Xiang, L. L., Zhao, L. L., Wang, Y. L., Zhang, L. Q. \& Lin, J. P. Synergistic effect of Y and Nb on the high temperature oxidation resistance of high $\mathrm{Nb}$ containing TiAl alloys. Intermetallics 27, 6-13 (2012).

26. Zhao, L. L. et al. Influence of $\mathrm{Y}$ addition on the long time oxidation behaviors of high $\mathrm{Nb}$ containing TiAl alloys at 900 degrees $\mathrm{C}$. Intermetallics 18, 1586-1596 (2010).

27. Douglass, D. L. A critique of internal oxidation in alloys during the post-wagner era. Oxidation of Metals 44, 81-111 (1995).

28. Maurice, V. et al. XPS study of the initial stages of oxidation of $\alpha_{2}-\mathrm{Ti}_{3} \mathrm{Al}$ and $\gamma$-TiAl intermetallic alloys. Acta Mater. 55, 3315-3325 (2007).

29. Kim, Y. W. Ordered intermetallic alloys. 3. Gamma-Titanium aluminides. JOM 46, 30-39 (1994)

30. Draper, S. L., Lerch, B. A., Locci, I. E., Shazly, M. \& Prakash, V. Effect of exposure on the mechanical properties of Gamma MET PX. Intermetallics 13, 1014-1019 (2005).

31. Birks, N., Meier, G. H. \& Pettit, F. S. Introduction to the High Temperature Oxidation of Metals. 23 (Cambridge University Press, 2006)

32. Shida, Y., Stott, F. H., Bastow, B. D., Whittle, D. P. \& Wood, G. C. Development of preferntial intergranular oxides in nickelaluminum alloys at high-temperatures. Oxidation of Metals 18, 93-113 (1982).

33. Gil, A., Hoven, H., Wallura, E. \& Quadakkers, W. J. The effect of microstructure on the oxidation behavior of TiAl-based intermetallic. Corrosion Sci. 34, 615-630 (1993).

34. Nelson, J. C. \& Oriani, R. A. Stress generation during anodic oxidation of titanium and aluminum. Corrosion Sci. 34, 307-326 (1993).

35. Leyens, C., Braun, R., Frohlich, M. \& Hovsepian, P. E. Recent progress in the coating protection of gamma titaniumm aluminides. JOM 58, 17-21 (2006).

36. Becker, S., Rahmel, A., Schorr, M. \& Schutze, M. Mechanism of isothermal oxidation of the intermetallic TiAl and of TiAl alloys. Oxidation of Metal 38, 425-464 (1992). 


\section{Acknowledgements}

The authors are grateful for the financial support provided by the National Nature Science Foundation of China (NSFC) (Grant Nos U1302275 and 51305304) and the Natural Sciences and Engineering Research Council of Canada (NSERC) in the form of international research collaboration. One of the authors (D.L. Chen) is also grateful for the financial support by the Premier's Research Excellence Award (PREA), NSERC-Discovery Accelerator Supplement (DAS) Award, Canada Foundation for Innovation (CFI), and Ryerson Research Chair (RRC) program.

\section{Author Contributions}

S.Q. Tang conducted the oxidation experiments. S.J. Qu, A.H. Feng, and J. Shen designed and supervised the project, and produced the samples. S.Q. Tang, S.J. Qu, A.H. Feng, J. Shen and D.L. Chen analyzed the data. C. Feng is S.Q. Tang's supervisor. J. Shen and D.L. Chen assessed the outcome. S.Q. Tang, A.H. Feng and D.L. Chen wrote the paper. All the authors discussed the results and commented on the manuscript.

\section{Additional Information}

Competing Interests: The authors declare that they have no competing interests.

Publisher's note: Springer Nature remains neutral with regard to jurisdictional claims in published maps and institutional affiliations.

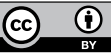

Open Access This article is licensed under a Creative Commons Attribution 4.0 International License, which permits use, sharing, adaptation, distribution and reproduction in any medium or format, as long as you give appropriate credit to the original author(s) and the source, provide a link to the Creative Commons license, and indicate if changes were made. The images or other third party material in this article are included in the article's Creative Commons license, unless indicated otherwise in a credit line to the material. If material is not included in the article's Creative Commons license and your intended use is not permitted by statutory regulation or exceeds the permitted use, you will need to obtain permission directly from the copyright holder. To view a copy of this license, visit http://creativecommons.org/licenses/by/4.0/.

(C) The Author(s) 2017 